\title{
RNA Interference: A Promising Molecular Tool for Insect Pest Control
}

ISSN: 2637-7659

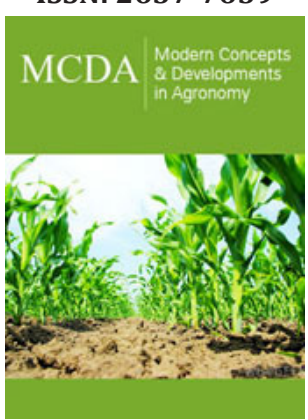

*Corresponding author: Wesley Pires Flausino Máximo, Department of Chemistry, Federal University of Lavras (UFLA), Lavras, 37.200-000, MG, Brazil

Submission: 畘 October 01, 2019

Published: 留November 22, 2019

Volume 5 - Issue 3

How to cite this article: Wesley $\mathrm{P} F$ M, Luciano V P. RNA Interference: A Promising Molecular Tool for Insect-Pest Control. Mod Concep Dev Agrono.5(3). MCDA.000614.2019.

DOI: 10.31031/MCDA.2019.05.000614

Copyright@ Wesley Pires Flausino Máximo, This article is distributed under the terms of the Creative Commons Attribution 4.0 International License, which permits unrestricted use and redistribution provided that the original author and source are credited.

\author{
Wesley Pires Flausino Máximo* and Luciano Vilela Paiva \\ Federal University of Lavras (UFLA), Brazil
}

\begin{abstract}
RNA interference (RNAi) is a natural mechanism found in most eukaryotes with great potential to be used in agricultural pest control. It is based primarily on gene silencing caused by double-stranded RNA (dsRNA) molecules which are complementary to the target messenger RNA (mRNA) in a highly specific manner. The major components of RNAi involve the presence of enzymes capable of recognizing the dsRNA molecule, cut it off in smaller fragments and finally binding the generated antisense strands to the target mRNA. Several research centers, universities, and private institutions have been working on better understand its functional mechanism to apply this molecular approach in insect pest control. As advantage, RNAi is considered a high specificity tool able to affect only the target organisms, unlike the broadspectrum chemical methods generally applied in the field. Furthermore, reports in literature have proved RNAi is potentially efficient to cause insect mortality for many insect orders. Taking this into account, our mini-review aims to provide some basic information on this subject and demonstrate the feasibility of applying RNAi as a molecular approach for controlling insect pests.
\end{abstract}

Keywords: RNAi; dsRNA; Gene silencing; Insect mortality; Pest control; Dicer; RISC

\section{Introduction}

\section{Mechanism of RNA-mediated interference}

RNA interference (RNAi) is a specific mechanism of knockdown or downregulation of gene expression mediated by the presence of double-stranded RNA (dsRNA) molecules capable of inducing a homologous target cellular messenger RNA (mRNA) response. Through the binding that occurs between complementary sequences, dsRNA can specifically reduce the abundance of target gene transcripts when introduced into the organism [1]. The main steps of interference in the regulation of gene expression involve the cleavage of dsRNA precursors into small interfering RNAs (siRNA) of approximately 21 to 25 nucleotides by the enzyme Dicer [2,3], incorporation of siRNAs into the RNA-induced silencing complex (RISC), and target complementary mRNA degradation by the catalytic components of RISC, known as Argonauts proteins, which use the antisense strand of siRNAs as an mRNA recognition template [4].

\section{Functional machinery of RNAi}

The functional machinery of this biological process has two major sets of components: (1) the intracellular core components, composed by the Dicer enzymes, RNA-binding factors and Argonaut proteins; and (2) the systemic components that amplify dsRNA signals in order to spread throughout body tissues [5]. In insects, two RNA-mediated silencing pathways are more known, one mediated by microRNAs (miRNAs) and the other by siRNAs [6]. The last has been widely used in in vitro experiments through dsRNA ingestion or injection bioassays focused on evaluating the decrease of gene expression and consequently the insect mortality.

\section{Barriers to RNAi efficiency}

There are a number of factors about RNAi that are not well-understood regarding the cellular machinery of many insects, and even those that have the ability to trigger gene silencing 
from dsRNA ingestion have other barriers that may hinder process efficiency. The main barriers include: (I) presence of nucleases, a group of enzymes capable of degrading nucleic acids present in the insects' intestinal contents [7,8]; (II) intestinal $\mathrm{pH}$, which is very variable between insect orders, and excess acidity or alkalinity can cause chemical and enzymatic hydrolysis of dsRNA molecules [9]; and (III) RNA concentration, since high amounts of dsRNA in the cell can saturate miRNA and siRNA silencing machinery, but low amounts may not be sufficient to trigger induction response [10].

\section{RNAi as a molecular tool for insect pest control}

Although these barriers certainly interfere in RNAi efficiency, there are reports of success in the literature demonstrating the reduction of gene expression levels via RNAi in insects and, in many cases, even leading them to death. These works have been done with different insect species from different orders such as Diabrotica virgifera virgifera LeConte (Coleoptera) [11,12], Helicoverpa armigera (Lepidoptera) [13], Reticulitermes flavipes (Isoptera) [14], Camponotus floridanus (Hymenoptera) [15], Agrilus planipennis (Coleoptera) [16], Leptinotarsa decemlineata (Coleoptera) [17], and likely much more works are coming ahead. The major dsRNA delivery methods widely employed in vitro experiments are based on microinjection, ingestion and soaking approaches [18], which are the initial tests performed in laboratory bioassays to verify the RNAi efficacy. However, for pest management purposes more dynamic strategies feasible to be applied at field level must be used. In this sense, new supports and delivery methods have been proposed to make sure that dsRNA may be available to get into contact with pests and simultaneously protected from degradation events generally found at environmental conditions. The new approaches include a variety of possibilities of affecting the pests such as the use of exosomes [19], liposomes [20], dsRNA absorption by roots [21] and even across bacteria-mediated dsRNA delivery [22]. This information increasingly highlights the importance of RNAi technology as an advanced, innovative mechanism for application in pest management. Even though the main goal of this review is to consider RNAi as a promising tool for insect pest control, it is evident that this technology is already a reality, taking into account there are facilities and/or companies that provide services involved on RNAiderived products that are either currently available to be used or in course. Some examples include the biotechnology-derived maize, MON87411, which expresses the DvSnf7 gene against western corn rootworm (D. virgifera) [23], and the services that companies like Green Light Biosciences (https://www.greenlightbiosciences. com/) and RNAgri (https://www.rnagri.com/) have provided for RNAi applications. Indeed, many other services and products will likely arise in the next coming years.

\section{Final considerations}

Nowadays, control of insect pests is based mainly on chemical compounds of wide spectrum. Given the damages that toxic components released by these chemicals on the environment could cause to human beings, and all biodiversity of plants, animals, and microorganisms, more sustainable alternative approaches have been greatly desired for the society. RNAi is a tool with great potential to be employed in this area as a replacement to the conventional methods, or even in parallel to reduce the number of chemicals used since many reports has shown its efficiency and capacity to induce mortality of a variety of insects in both in vitro and on-field experiments. Furthermore, considering that the mechanism of action of RNAi focuses specifically on silencing genes belonging to the target organism, the chance of affecting off-targets or beneficial insects become substantially remote.

Taking into account all factors that may influence the success of the RNAi mechanism, one of the most important steps is choosing the target gene to be silenced. Generally, genes that are potential targets of dsRNA molecules are those that encode functional proteins considered essential in the cell $[11,16,24]$, that is, proteins that perform activities crucial to the proper functioning of metabolism. Through in-depth research in the literature and studies focused on the target insects, it is possible to find gene families that may be involved in biological processes important for maintaining cell balance, and then induce the inhibition and/or silencing of genes responsible for coding functional proteins required for pest survival. Upon choosing the most suitable gene to silence plus the proper dsRNA delivery method to target insects, it is well likely that RNAi could be increasingly applied as a promising tool to control a great diversity of insect pests.

\section{Conflict of interest}

The authors declare no conflict of interest.

\section{References}

1. Fire A, Xu S, Montgomery MK, Kostas SA, Driver SE, et al. (1998) Potent and specific genetic interference by double-stranded RNA in Caenorhabditis elegans. Nature 391(6669): 806-811.

2. Baulcombe D (2004) RNA silencing in plants. Nature 431(7006): 356363.

3. Katoch R, Sethi A, Thakur N, Murdock LL (2013) RNA for insect control: current perspective and future challenges. Appl Biochem Biotechnol 171(4): 847-873.

4. Meister G, Tuschl T (2004) Mechanisms of gene silencing by double-stranded RNA. Nature 431(7006): 343-349.

5. Siomi H, Siomi MC (2009) On the road to reading the RNA-interference code. Nature 457(7228): 396-404.

6. Tomari Y, Du T, Zamore PD (2007) Sorting of Drosophila small silencing RNAs. Cell 130(2): 299-308.

7. Arimatsu Y, Kotani E, Sugimura Y, Furusawa T (2007) Molecular characterization of a cDNA encoding extracellular dsRNase and its expression in the silkworm, Bombyx mori. Insect Biochem Mol Biol 37(2): 176-183.

8. Katoch R, Thakur N (2012) Insect gut nucleases: a challenge for RNA interference mediated insect control strategies. Int J Biochem Biotechnol 1(8): 198-203.

9. Price DR, Gatehouse JA (2008) RNAi-mediated crop protection against insects. Trends Biotechnol 26(7): 393-400.

10. Tomoyasu Y, Miller SC, Tomita S, Schoppmeier M, Grossmann D, et al. (2008) Exploring systemic RNA interference in insects: a genome-wide survey for RNAi genes in Tribolium. Genome Biol 9(1): R10.

11. Baum JA, Bogaert T, Clinton W, Heck GR, Feldmann P, et al. (2007) Control of coleopteran insect pests through RNA interference. Nat Biotechnol 25(11): 1322-1326. 
12. Bolognesi R, Ramaseshadri P, Anderson J, Bachman P, Clinton W, et al. (2012) Characterizing the Mechanism of Action of Double-Stranded RNA Activity against Western Corn Rootworm (Diabrotica virgifera virgifera LeConte). PLoS One 7(10): e47534.

13. Asokan R, Sharath Chandra G, Manamohan M, Krishna Kumar NK, Sita T (2014) Response of various target genes to diet-delivered dsRNA mediated RNA interference in the cotton bollworm, Helicoverpa armigera. J Pest Sci 87(1):163-172.

14. Zhou X, Wheeler MM, Oi FM, Scharf ME (2008) RNA interference in the termite Reticulitermes flavipes through ingestion of double-stranded RNA. Insect Biochem Mol Biol 38(8): 805-815.

15. Ratzka C, Gross R, Feldhaar H (2013) Gene expression analysis of the endosymbiont-bearing midgut tissue during ontogeny of the carpenter ant Camponotus floridanus. J Insect Physiol 59(6): 611-623.

16. Rodrigues TB, Rieske LK, Duan JJ, Mogilicherla K, Palli SR (2017) Development of RNAi method for screening candidate genes to control emerald ash borer, Agrilus planipennis. Sci Rep 7(7379): 1-8.

17. Clements J, Schoville S, Peterson N, Huseth AS, Lan Q et al. (2017) RNA interference of three up-regulated transcripts associated with insecticide resistance in an imidacloprid resistant population of Leptinotarsa decemlineata. Pestic Biochem Phys 135: 35-40.

18. Yu N, Christiaens O, Liu J, Niu J, Cappelle K, et al. (2012) Delivery of ds-
RNA for RNAi in insects: an overview and future directions. Insect Sci 20(1): 4-14.

19. Darband SG, Mirza Aghazadeh AM, Kaviani M, Mihanfar A, Sadighparvar S, et al. (2018) Exosomes: natural nanoparticles as bio shuttles for RNAi delivery. J Control Release 289: 158-170.

20. Taning CNT, Christiaens O, Berkvens N, Casteels H, Maes M, et al. (2016) Oral RNAi to control Drosophilla suzukii: laboratory testing against larval and adult stages. Journal of Pest Science 89(3): 803-814.

21. Andrade EC, Hunter WB (2016) RNA Interference-Natural Gene-Based Technology for Highly Specific Pest Control (HiSPeC), RNA Interference, Ibrokhim Y Abdurakhmonov, IntechOpen.

22. Whitten MM, Facey PD, Del Sol R, Fernandéz Martínez LT, Evans MC, et al. (2016) Symbiont-mediated RNA interference in insects. Proc Biol Sci 283(1825): 20160042.

23. Moar W, Khajuria C, Pleau M, Ilagan O, Chen M, et al. (2017) Cry3Bb1-Resistant Western Corn Rootworm, Diabrotica virgifera virgifera (LeConte) Does Not Exhibit Cross-Resistance to DvSnf7 dsRNA. PLoS One 12(1): e0169175.

24. Ulrich J, Dao VA, Majumdar U, Schmitt Engel C, SchwirzJ, et al. (2015) Large scale RNAi screen in Tribolium reveals novel target genes for pest control and the proteasome as prime target. BMC Genomics 16(674): $1-9$.

For possible submissions Click below:

Submit Article 